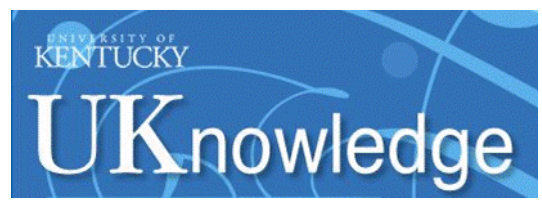

University of Kentucky

UKnowledge

$12-2017$

\title{
Influence of Dietary Salt Knowledge, Perceptions, and Beliefs on Consumption Choices After Stroke in Uganda
}

\author{
Martin N. Kaddumukasa \\ Makerere University, Uganda \\ Elly Katabira \\ Makerere University, Uganda \\ Martha Sajatovic \\ University Hospitals Case Medical Center \\ Svetlana Pundik \\ Case Western Reserve University \\ Mark Kaddumukasa \\ Makerere University, Uganda
}

See next page for additional authors

Follow this and additional works at: https://uknowledge.uky.edu/neurology_facpub

Part of the African Studies Commons, Diseases Commons, Neurology Commons, and the Nutrition

\section{Commons}

Right click to open a feedback form in a new tab to let us know how this document benefits you.

\section{Repository Citation}

Kaddumukasa, Martin N.; Katabira, Elly; Sajatovic, Martha; Pundik, Svetlana; Kaddumukasa, Mark; and Goldstein, Larry B., "Influence of Dietary Salt Knowledge, Perceptions, and Beliefs on Consumption Choices After Stroke in Uganda" (2017). Neurology Faculty Publications. 29.

https://uknowledge.uky.edu/neurology_facpub/29

This Article is brought to you for free and open access by the Neurology at UKnowledge. It has been accepted for inclusion in Neurology Faculty Publications by an authorized administrator of UKnowledge. For more information, please contact UKnowledge@lsv.uky.edu. 


\section{Influence of Dietary Salt Knowledge, Perceptions, and Beliefs on Consumption Choices After Stroke in Uganda}

\section{Digital Object Identifier (DOI)}

https://doi.org/10.1016/j.jstrokecerebrovasdis.2017.07.016

\section{Notes/Citation Information}

Published in Journal of Stroke \& Cerebrovascular Diseases, v. 26, issue 12, p. 2935-2942.

(c) 2017 National Stroke Association. Published by Elsevier Inc. All rights reserved.

This manuscript version is made available under the CC-BY-NC-ND 4.0 license

https://creativecommons.org/licenses/by-nc-nd/4.0/.

The document available for download is the author's post-peer-review final draft of the article.

\section{Authors}

Martin N. Kaddumukasa, Elly Katabira, Martha Sajatovic, Svetlana Pundik, Mark Kaddumukasa, and Larry B. Goldstein 
Published in final edited form as:

J Stroke Cerebrovasc Dis. 2017 December ; 26(12): 2935-2942. doi:10.1016/j.jstrokecerebrovasdis.

2017.07.016.

\title{
INFLUENCE OF DIETARY SALT KNOWLEDGE, PERCEPTIONS AND BELIEFS ON CONSUMPTION CHOICES AFTER STROKE IN UGANDA
}

\author{
Martin N. Kaddumukasa, MD ${ }^{1}$, Elly Katabira, MD, FRCP ${ }^{1}$, Martha Sajatovic, MD, PHD ${ }^{2}$, \\ Svetlana Pundik, MD, MS ${ }^{3}$, Mark Kaddumukasa, MD ${ }^{1}$, and Larry B. Goldstein, MD, FAAN, \\ FANA, FAHA ${ }^{4}$
}

${ }^{1}$ Makerere University, College of Health Sciences, Kampala, Uganda ${ }^{2}$ University Hospitals Case Medical Center, Cleveland OH, USA ${ }^{3}$ Cleveland VA Medical Center and Case Western Reserve University, Cleveland OH, USA ${ }^{4}$ University of Kentucky, Lexington, Kentucky, USA

\section{Abstract}

Background-Previous research on Uganda's post-stroke population revealed that their level of dietary salt knowledge did not lead to healthier consumption choices.

Purpose-Identify barriers and motivators for healthy dietary behaviors and evaluate the understanding of widely accepted salt regulation mechanisms among post-stroke patients in Uganda.

Methods-Convergent parallel mixed methods triangulation design comprised a cross sectional survey $(n=81)$ and 8 Focus Group Discussions with 7-10 post-stroke participants in each group. We assessed participant characteristics and obtained insights into their salt consumption attitudes, perceptions and knowledge. Qualitative responses were analyzed using an inductive approach with thematic analytic procedures. Relationships between healthy dietary salt compliance, dietary salt knowledge and participant characteristics were assessed using logistic regression analyses.

Results-Healthy dietary salt consumption behaviors were associated with basic salt knowledge $(p<0.0001)$ but no association was found between compliance and salt-disease related knowledge $(p=0.314)$. Only $20 \%$ and $7 \%$ obtained health-related salt knowledge from their health facility and educational sources, respectively, whereas $44 \%$ obtained this information from media personalities; $92 \%$ of participants had no understanding of nutrition labels and only $25 \%$ of the

Corresponding author: Martin N. Kaddumukasa, MD, Makerere University, College of Health Sciences, P. O. Box 7076, Kampala, Uganda, PH: + 256772120965, kaddumart@yahoo.com.

Research Institution:

Department of Medicine, Makerere University College of Health Sciences, Kampala, Uganda

Disclosures

None.

Publisher's Disclaimer: This is a PDF file of an unedited manuscript that has been accepted for publication. As a service to our customers we are providing this early version of the manuscript. The manuscript will undergo copyediting, typesetting, and review of the resulting proof before it is published in its final citable form. Please note that during the production process errors may be discovered which could affect the content, and all legal disclaimers that apply to the journal pertain. 
study population consumed potash - an inexpensive salt substitute that is both rich in potassium and low in sodium.

Conclusion-One barrier to healthy dietary consumption choices among Uganda's stroke survivors is a lack of credible disease-related information. Improving healthcare provider strokerelated dietary knowledge in Uganda and encouraging the use of potash as a salt substitute would help reduce hypertension and thereby lower the risk of stroke.

\section{Keywords}

Sodium; Dietary Salt; Stroke; Hypertension; Sub-Saharan Africa; Uganda

\section{Introduction}

High salt consumption is an important determinant of hypertension and cardiovascular risk, having a population-attributable risk for hypertension of 9-17\% (1, 2). According to World Health Organization (WHO) statistics, over $80 \%$ of cardiovascular disease (CVD) deaths occur in low-and middle-income countries with high blood pressure as a major contributor (3). In Uganda, more than $65 \%$ of post-stroke patients have uncontrolled hypertension (4). Decreasing blood pressure on a population level is one strategy for reducing the rate of CVDs $(5,6)$. Lowering dietary salt consumption is a potentially effective approach for decreasing blood pressure and thereby the risk of stroke and cardiovascular diseases (7). Well in excess of the WHO recommendation of $5 \mathrm{~g} / \mathrm{d}(8), 65 \%$ of Uganda's post-stroke population registered $24 \mathrm{~h}$ urine sodium levels $\geq 8.5 \mathrm{~g} / \mathrm{d}(9)$.

Multiple factors including culture, patient age, educational level and income contribute to dietary behaviors (10). In Uganda, knowledge of the impact of diet on stroke risk as well as perceptions of stroke prevention are generally poor (4); however, even the limited dietary salt knowledge that exists is not associated with either healthy consumption choices or BP control (9). Studies assessing the disparity between knowledge and healthy behaviors in Uganda are not available. The data are crucial in resource limited settings such as Uganda in which chronic disease-care costs are prohibitive, making effective, inexpensive primary prevention interventions an imperative. The main objectives of the present study were to explore Ugandan's knowledge, attitudes, and behaviors related to their salt consumption decisions after stroke, identify barriers and motivators to healthy dietary compliance, and examine participants' understanding of widely accepted salt regulation mechanisms including the use of salt substitutes and interpretation of nutrition labels. We hypothesize that stroke survivors do not fully understand the risks associated with high salt consumption and are largely unaware of related health effects.

\section{Methods}

\section{Study design}

Data were collected between July 2015 and January 2016 at Uganda's Mulago National Referral Hospital. The hospital's neurology clinic serves as a tertiary referral center for neurologic disorders for the entire country. We utilized a mixed methods triangulation design(11) to obtain complementary data on stroke, patient salt consumption behaviors and 
associated motivating factors. We used quantitative data to measure patient salt-related dietary knowledge and associated behaviors and to assess the demographic and clinical characteristics of stroke survivors within the Stroke Clinic. Qualitative data was used to provide context for the interpretation of the quantitative data by determining patient perceptions and inform how identified gaps might be addressed. Focus Group Discussions (FGDs) to obtain qualitative data were moderated by an experienced qualitative researcher who was fluent in English and Luganda (the area's main local language). FGDs were conducted to give in-depth insights into the beliefs, attitudes and knowledge pertaining to the participant's salt consumption and their knowledge of its impact on health. All participants were adult (>18years) post-stroke patients identified from neurology and other medical data files using purposive sampling. Stroke was defined as a neurologic deficit of abrupt onset lasting more than 24-hrs, localizable to a vascular territory and attributable to a vascular cause with compatible findings on brain CT scan (4).

\section{Focus Group Methods}

A total of 8 focus groups were formed, each including 7-10 adults selected by purposive sampling with a history of stroke or an attendant with at least some responsibility for caring for a stroke affected participant $(n=81)$. Patients who could not provide a reliable history or did not have an attendant and those who declined consent were excluded. The topics for the FGDs were identified after a preliminary analysis of qualitative results from a test group of 5 post-stroke subjects and included respondents' understanding of 'sodium', perceptions and attitudes towards salt consumption, level of dietary salt knowledge, salt measurement and regulation, salt substitutes and nutrition labels. Group interviews were conducted to stimulate interaction, encourage participants to respond and react to each other, and compare experiences (12). Questions were open-ended so as not to limit the range/breadth of discussion. Participants were positioned so that each could have eye contact with others in the group. Each interview lasted approximately 60 minutes, was recorded, and then transcribed verbatim. Information collected from focus group sessions included interview and observation. Figure 3 gives an overview of the semi-structured interview protocol.

Salt knowledge was assessed in three ways: 1) basic knowledge (quantified by whether the subject is aware of the harm high salt has on general health); 2) diet-disease related knowledge (quantified by responses to the question ' what is the impact of high salt on health?)'; and 3) procedural knowledge (quantified by patient report on deliberate actions taken to cut down their salt intake).

\section{Qualitative Analysis}

The focus group transcripts were first read in their entirety to gain familiarity with the data. Segments of text were labeled and assigned codes that described meaning of content (13). The codes were subsequently collapsed into broad themes or categories. Finalization of codes was based on the consensus of the qualitative team.

\section{Quantitative Analysis}

Quantitative data were entered into a database, checked for consistency, and analyzed using the Statistical Package for the Social Sciences (SPSS) program software (version 22.0) with 
descriptive statistics summarized in text and tables. Fisher's Exact tests followed by multivariate logistic regression was used to determine the association between healthy dietary salt behaviors and salt-related knowledge. We adjusted for factors that could influence diet such as education, sex, location, post-stroke duration, type of stroke and stroke recurrence. All variables significant in the univariate analysis at $\mathrm{p} \$ 0.25$ were included in the multiple logistic regression analysis to identify those independently associated with healthy dietary salt compliance.

After analyzing the qualitative and quantitative datasets, the results from each were compared to identify areas of convergence (similarity) and divergence (difference).

\section{Quality control}

The study tools (questionnaire, FGD guide and checklist) were pretested and revised accordingly. Experienced FGD facilitators were trained on the objectives of the study and how to administer the tools. All interviews were undertaken in private rooms offering confidentiality.

\section{Ethical considerations}

The study was approved by the Makerere University School of Medicine Research and Ethics Committee and the Uganda National Council for Science and Technology. Informed written and verbal consent was obtained for the surveys and FGDs, respectively. Confidentiality and use of data for research purposes was emphasized at point of recruitment.

\section{Results}

There were 81 post-stroke subjects enrolled aged 17 to 87 years, of whom $34.6 \%(n=28)$ were men and $65.4 \%(n=53)$ were women. The average age of participants was $57.1 \pm 15.7$ years with a plurality $40.7 \%$ aged above 60 years. The mean interval between the index stroke and the interview was 3.0 \pm 3.3 years with $19.8 \%$ reporting recurrent stroke episodes. The majority of respondents (59.3\%) reported having little or no formal education with men more highly educated than the women (OR=4.57 95\% CI $1.72-12.05 ; \mathrm{p}=0.002)$.

Table 1 gives the demographic and clinical characteristics of the participants by group according to the odds of salt-disease related knowledge. Men and those with a history of hemorrhagic stroke were more likely to have adequate salt-disease knowledge than women and those with ischemic stroke.

Based on the content of the analyzed data, derived predominant perceptions were summarized under six themes related to dietary salt consumption. Each theme is described and representative quotes illustrating prevailing perceptions are reported in italics. Responses in local language were translated into English by a translator. Table 2 provides key quotations representative of each theme. 


\section{Sodium knowledge}

Participants were asked for their understanding of the term 'sodium' and its relationship with dietary salt. The majority (93\%) had no understanding of the term. Only $7 \%$, all of whom were highly educated, were able to articulate the relationship between sodium and common salt.

\section{Dietary salt consumption - perception and attitudes}

Respondents had mixed attitudes about dietary salt consumption. The majority considered salt an essential seasoning and food with low salt as inedible. A few reported raw salt as bad but regarded it as necessary for certain foods such as eggs and roasted food.

High salt was recognized as having an adverse impact on health by $89 \%$ of participants; however, $38 \%$ related that they secretly add salt to their food. Only $37 \%$ reported adhering to dietary recommendations.

The majority of male participants indicated leaving decisions on amounts of salt consumed to their caretakers (spouses). They expressed indifference to the salt amounts served in their food. In contrast, female participants indicated more responsibility and ownership of their salt consumption decisions even when they were entirely dependent on a caretaker.

Of all participants, $24 \%$ considered consumption of raw salt as more hazardous than a consistent high salt diet. The immediate effects of high salt consumption were reported as heart burn (35\%), headache (36\%), unusually high urinating frequency (15\%), palpitations (22\%), burning feeling on tongue (10\%) and over sweating (4\%).

Perceptions on how dietary salt can lead to health problems included erroneous suppositions of salt accumulating and blocking off blood vessels causing stroke and salt causing accumulation of fats in the body.

Nearly three quarters of participants (72\%) reported being indifferent to the amount of salt they consumed prior to stroke and only changed their attitude and consumption decisions after their stroke. Figure 4 summarizes the sub-themes under perceptions and attitudes in terms of percentage count recording these opinions.

\section{Dietary salt knowledge}

An analysis of knowledge of the study group participants pertaining to salt and its impact on health found that a majority (51.9\%) had basic knowledge that high salt is harmful to health, but only $14.8 \%$ knew the reasons for this risk. The majority reported being told by their doctors that salt was bad for their post-stroke condition, but did not specifically know why. Participants whose responses to the question ' what is the impact of high salt on health?' included both high blood pressure and stroke were considered to have sufficient salt-disease related knowledge; responses excluding either condition were considered to indicate a knowledge gap. There was a significant association between healthy dietary salt compliance behavior and basic salt knowledge $(p<0.0001)$ but no association found between this compliance and salt-disease related knowledge $(p=0.314)$. Univariate chi-square analysis showed relationship between low salt dietary compliance and basic salt knowledge 
(unadjusted OR 14.2, $p<0.0001$ ). The relationship remained significant after adjustment for variables with $\mathrm{p} \unlhd$. .25 in the univariate analyses (sex, marital status, location, stroke type and post-stroke duration; adjusted OR 21.8, $p<0.0001$ ). Similar analysis found no association between low salt dietary compliance and salt-disease knowledge (unadjusted OR 1.88, $\mathrm{p}=0.319$; adjusted $\mathrm{OR} 2.69, \mathrm{p}=0.181$ ). Table 3 gives the results of the multivariate logistic regression analysis for healthy dietary salt compliance and salt knowledge.

Only $31 \%$ and $20 \%$ of participants, respectively, correctly related high salt consumption to hypertension and stroke. Other side effects were reported as diabetes (6\%), organ damage (liver, kidney, lungs) (20\%) and increased body fat (5\%); 26\% of participants indicated they did not know the answer.

To reduce the amount of salt in their bodies or in the meals they eat, participants reported eating food with minimal $(63 \%)$ or completely devoid of salt (20\%), drinking lots of water after high salt meals (40\%), adding sugar to high salt meals (10\%), adding water to dilute high salty food (35\%), forgoing salty soup in favor of dry food (12\%), eating fruits with salty meals e.g. mangoes, avocado or bitter berries (6\%) and opting for fresh foods as opposed to junk food (51\%).

\section{Dietary salt measurement and regulation}

No stroke survivor could articulate a specific recommended dietary salt consumption target. They agreed on the need to consume 'very little salt', but were unable to quantify how much. Reported dietary salt measurement units were derived from a combination of cooking experience, cultural inferences and intuition - from tablespoons, palm measurements to pinches.

\section{Salt substitutes}

Respondents reported utilizing a wide variety of salt types and salt substitutes including alkaline salt deposits from Lake Magadi (11\%), unrefined crater lake salt from Lake Katwe (7\%), Iodized salt (47\%), non iodized salt (27\%), potash- ash from burnt banana peels \& stems, pawpaw stems (25\%) and Lemon extract (15\%). Their information sources included TV/radio shows (44\%), knowledge passed on from elders (11\%), post-stroke peers (18\%), medical personnel (20\%) and school (7\%).

\section{Nutrition labels}

A total of $92 \%$ of respondents had no knowledge of nutrition labels or their interpretation; only $8 \%$ used these labels to determine whether food items were salty vs sweet, and/or savory vs hot. Reasons listed for the failure of participants to utilize nutrition labels to inform respondents' food choices included: 1) respondents' inability to read (16\%); 2) inability to understand food label values (38\%); and 3) lack of nutrition labels on local food products $(62 \%)$. 


\section{Discussion}

Understanding salt knowledge, attitudes and behaviors related to dietary salt consumption may provide insights into the likely effectiveness of education-based programs (14). There were four key findings from our study: 1, the vast majority of stroke survivors ( $>80 \%)$ had minimal knowledge on the relationship between salt consumption and stroke risk; 2, dietary health knowledge is mainly derived from non-medical, non-educational sources; 3 , current food/sodium labeling schemes in Uganda are inadequate; and 4, stroke survivors' use of salt substitutes may be key to feasible hypertension and stroke control in this population.

Misperceptions regarding the effects of high salt on health among participants included causing diabetes, hypercholesterolemia, headaches, heartburn, and excessive sweating. Our findings are consistent with a New Zealand study in which factual awareness of health conditions associated with high salt was similarly low (15).

Participants' attitudes towards dietary salt were examined as influencers of their consumption choices. Whereas $89 \%$ of post-stroke participants indicated that a high salt diet could lead to serious health problems, $26 \%$ considered added salt as necessary to make certain foods palatable and $38 \%$ reported adding table salt to improve flavor. Even with some knowledge of the hazards of high salt, it is hard for these participants to overcome prior consumption habits. Salt addiction is in part physiological as a high salt diet down regulates taste buds, allowing habituation and resulting in the need for higher salt concentrations to provide the "saltiness" reward (16).

Only $31 \%$ were able to correctly relate high salt and hypertension. This percentage is very low when compared with a $40.7 \%$ proportion of participants with a post-stroke duration of $>2 \mathrm{yrs}$ over which time they are expected to have interacted with health personnel on repeat visits (a minimum of 6-times per year). A survey conducted in Europe and Australia found that as many as $80 \%$ of residents knew the relationship between high salt intake and hypertension (14). In another study, 95\% of participants identified the seriousness of a high salt diet on health with $81 \%$ linking it to raised blood pressure (17), indicating that there is still great potential for improvement in Uganda, especially in high risk, post-stroke patients. These differences may be explained by a deliberate effort in the more developed countries to drive salt awareness strategies primarily at patient stroke care points aimed specifically at high risk patients which is absent in Uganda.

Only $14.8 \%$ of study participants had adequate salt-disease related knowledge. Of these, men had better salt-disease knowledge than women, possibly related to their higher levels of education. Those with a history of hemorrhagic stroke were more knowledgeable than those with a history of ischemic stroke. We speculate that better knowledge among those with hemorrhagic stroke may be because hemorrhagic stroke is strongly associated with greater stroke severity, higher mortality, and poorer long-term neurologic outcomes (18). This may relatively increase the importance disease-related information among these patients.

Patients with lower disease specific knowledge report a lower quality of life, and have poorer health related outcomes (19). The salt-disease knowledge registered in this study is low compared to prior knowledge results of $39 \%$ on this same population (9). The disparity 
may be attributed to differences in study methodology. The questionnaire from the cross sectional study provided subjects with response options whereas questions in the focus group discussion were open-ended (12). None of the respondents were able to articulate an optimal salt target indicating a fundamental lack of procedural knowledge. Even with health providers advocating reduced salt consumption, respondents reported having no specific information on target values and associated measurement units. Although 37\% report strict adherence to dietary recommendations, without accurate knowledge of consumption targets, the probability of success is low. Limited salt knowledge coupled with erroneous medical information highlighted by this study partly explains the absence of a positive relationship between salt knowledge and behavior (9).

Participants reported that their primary sources of stroke-disease information were nonmedical media personalities and post-stroke peers. In addition, education provided by medical personnel was found to have little in way of diet recommendations or salt targets. Although a high number of post-stroke patients report consuming little salt, it is not reflected in their $24 \mathrm{~h}$ urine sodium (9). Inadequate access to credible disease information is a key barrier to healthier consumption choices. That only $20 \%$ of participants in this study identified interaction with medical professionals as a source of stroke and hypertension control knowledge is a reflection of the poor level of purposeful and educative interaction between health workers and patients (20). It may also point to a lack of sufficient disease knowledge on the part of health workers in Uganda. A study in Pakistan found that junior and future doctors had poor hypertension knowledge leading to sub-optimal management of hypertension cases (21). Another study in Iran showed only $20 \%$ of physicians could properly manage a patient with hypertension (22). There is, therefore, a need in these environments to provide healthcare providers with holistic hypertension case management knowledge that is more than medication but also includes dietary (salt) lifestyle changes to share with their patients.

Only $8 \%$ were familiar with the concept of nutrition labels while $7 \%$ had an understanding of the term 'sodium' as it is reported on food labels; $38 \%$ were unable to read deriving no value from the food labels. Less educated respondents are less likely to check nutrition labels as an aid to lower salt intake $(23,24)$. To increase the value of food labels, there is need for a system that makes the salt content of foods easily apparent regardless of consumers' ability to read (25). A scheme that includes color-coded interpretation of nutrient levels is most likely to help consumers identify at a glance those foods low in salt (26). Improved nutrition knowledge associated with food labels may support healthier food choices (27).

Of the participants, $18 \%$ reported using naturally occurring salts versus processed table salt. Although they contain a higher trace mineral content than refined table salt, there no is difference in their sodium content (8). Therefore, natural salts consumed in the same amounts as table salt will not achieve salt reduction targets.

Salt substitutes replace some or all of the sodium with potassium (29), which is associated with lower blood pressures (30). An important portion of our study population (25\%) reported using potash- ash from burnt banana stems and pawpaw stems as a viable salt 
substitute. Banana is the most farmed fruit in Uganda (31). In rural parts of Uganda, their stems are cut up, sundried and then burnt for ash extract composed of $\sim 46 \%$ potassium and $\sim 2.6 \%$ sodium. It has been used as a food additive and salt substitute for generations in other places including West Africa and India $(32,33)$. Inexpensive and readily available, its incorporation in salt reduction campaigns and possible commercialization could help Uganda's population achieve salt reduction targets.

There are some limitations to the generalizability of the present results. We used a convenience sample $(n=81)$ that is not necessarily representative of the wider Ugandan community. Its relatively small size meant we could not explore knowledge, perceptions or preferences among people of different ethnicities or socio-economic status. In addition, an overrepresentation of women in the study sample occurred as a result of the sampling methodology. This was due to greater willingness among women to participate. Participation bias could also occur if those more or less severely affected were more likely to participate.

To address the identified barriers to healthy dietary behaviors among Uganda's stroke survivors, there is an urgent need to make healthcare providers the primary sources of accurate stroke and hypertension control knowledge. This should be coupled with equipping these providers with evidence-based diet-related information. There is also value to be had from harnessing the existing correct information in the population such as use of potash. Education regarding sodium replacement and salt substitution is feasible and has the potential to improve blood pressure control and reduce the burden of stroke and other cardiovascular diseases in the country. Furthermore, future research is needed to evaluate the impact of dietary behavioral change programs on patient outcomes.

\section{Acknowledgments}

Grant Support:

- $\quad$ National Institute of Neurological Disorders and Stroke of the National Institute of Health (Award R25NS080968)

- $\quad$ Fogarty International Centre of the National Institutes of Health (Award VUMC41965)

\section{Sources of Funding}

This research was supported by the National Institute of Neurological Disorders and Stroke of the National Institute of Health (Award R25NS080968) and the Fogarty International Centre of the National Institutes of Health (Award VUMC41965) in a joint collaboration with Makerere University, College of Health Sciences.

\section{References}

1. Strazzullo P, D'Elia L, Kandala NB, Cappuccio FP. Salt intake, stroke, and cardiovascular disease: meta-analysis of prospective studies. BMJ. 2009; 339:b4567. [PubMed: 19934192]

2. Charlton K, Yeatman H, Houweling F, Guenon S. Urinary sodium excretion, dietary sources of sodium intake and knowledge and practices around salt use in a group of healthy Australian women. Australian and New Zealand journal of public health. 2010; 34(4):356-63. [PubMed: 20649774]

3. Fuster V, Bansilal S. Promoting cardiovascular and cerebrovascular health. Stroke. 2010; 41(6): 1079-83. [PubMed: 20498452]

4. Kaddumukasa M, Ddumba E, Duncan P, Goldstein LB. Poststroke hypertension in Africa. Stroke. 2012; 43(12):3402-4. [PubMed: 23010675] 
5. WHO. [Accessed 20/5/2017] A global brief on hypertension Silent killer, global public health crisis. 2013. p. 40Available from: http://www.who.int/cardiovascular_diseases/publications/ global_brief_hypertension/en/

6. Sookram C, Munodawafa D, Phori PM, Varenne B, Alisalad A. WHO's supported interventions on salt intake reduction in the sub-Saharan Africa region. Cardiovascular diagnosis and therapy. 2015; 5(3):186-90. [PubMed: 26090329]

7. Katherine, S., Sonja, N., Toni, S., Valdeep, G., Beverley, B., Sarah, T., et al. [Accessed 16/9/2016] Assessment of dietary sodium in adults (aged 19 to 64 years) in England london. National Diet and Nutrition Survey [Internet]. 2011. Available from: www.gov.uk/government/uploads/system/ uploads/attachment_data/file/213420/Sodium-Survey-England-2011

8. Ha SK. Dietary salt intake and hypertension. Electrolyte Blood Press. 2014; 12(1):7-18. [PubMed: 25061468]

9. Kaddumukasa MN, Katabira E, Sajatovic M, Pundik S, Kaddumukasa M, Goldstein LB. Influence of sodium consumption and associated knowledge on poststroke hypertension in Uganda. Neurology. 2016; 87(12):1198-205. [PubMed: 27558374]

10. Lallukka T, Laaksonen M, Rahkonen O, Roos E, Lahelma E. Multiple socio-economic circumstances and healthy food habits. European journal of clinical nutrition. 2007; 61(6):701-10. [PubMed: 17180154]

11. Creswell, J., Plano, C., Gutmann, M., Hanson, E. Advance mixed methods research designs. Tashakkori, A., Teddlie, C., editors. Thousand Oaks CA: SAGE; 2003. p. 209-40.

12. McCluskey A, Vratsistas-Curto A, Schurr K. Barriers and enablers to implementing multiple stroke guideline recommendations: a qualitative study. BMC health services research. 2013; 13:323. [PubMed: 23958136]

13. Creswell, JW. Choosing among five approaches. 2. Thousand Oaks California: Sage; 2007. qualitative inquiry and research designs; p. 35-41.

14. Land MA, Jeffery P, Webster J, Crino M, Chalmers J, Woodward M, et al. Protocol for the implementation and evaluation of a community-based intervention seeking to reduce dietary salt intake in Lithgow, Australia. BMC public health. 2014; 14:357. [PubMed: 24731226]

15. Wyllie, A., Moore, R., Brown, R. [Accessed 20/4/2016] Salt consumer survey. 2011. Available from: www.foodsafety.govt.nz/elibrary/industry/salt-survey.pdf

16. Cappuccio FP, Markandu ND, MacGregor GA. Dietary salt intake and hypertension. Klinische Wochenschrift. 1991; 69(Suppl 25):17-25. [PubMed: 1921246]

17. Charlton K, Steyn K, Levitt D, Nasheeta P. A food-based dietary strategy lowers blood pressure in a low socio-economic setting: a randomised study in South Africa. Public health nutrition. 2008; 11(12): $1-4$.

18. Chiu D, Peterson L, Elkind MS, Rosand J, Gerber LM, Silverstein MD. Comparison of outcomes after intracerebral hemorrhage and ischemic stroke. J Stroke Cerebrovasc Dis. 2010; 19(3):225-9. [PubMed: 20434051]

19. Sampson UK, Amuyunzu-Nyamongo M, Mensah GA. Health promotion and cardiovascular disease prevention in sub-Saharan Africa. Progress in cardiovascular diseases. 2013; 56(3):344-55. [PubMed: 24267442]

20. Akinyemi RO, Ogah OS, Ogundipe RF, Oyesola OA, Oyadoke AA, Ogunlana MO, et al. Knowledge and perception of stroke amongst hospital workers in an African community. European journal of neurology. 2009; 16(9):998-1003. [PubMed: 19486134]

21. Ranawaka UK, de Silva H, Balasuriya J, Puvanendiran S, Jayasekara B, Wijesekera JC. Stroke awareness in a Sri Lankan community. Journal of the Ceylon College of Physicians. 2016; (47): $31-5$.

22. Zibaeenezhad M, Babaee H, Vakili S. Knowledge, attitude and practice of general physicians in treatment and complications of hypertension in Fars province, southern Iran. Iran Red Crescent Med J. 2007; 9(1):4-8.

23. Levings JL, Maalouf J, Tong X, Cogswell ME. Reported use and perceived understanding of sodium information on US nutrition labels. Preventing chronic disease. 2015; 12:E48. [PubMed: 25855991] 
24. Nasreddine L, Akl C, Al-Shaar L, Almedawar MM, Isma'eel H. Consumer knowledge, attitudes and salt-related behavior in the Middle-East: the case of Lebanon. Nutrients. 2014; 6(11):5079102. [PubMed: 25401502]

25. Liem DG, Miremadi F, Zandstra EH, Keast RS. Health labelling can influence taste perception and use of table salt for reduced-sodium products. Public health nutrition. 2012; 15(12):2340-7. [PubMed: 22397811]

26. Webster JL, Li N, Dunford EK, Nowson CA, Neal BC. Consumer awareness and self-reported behaviours related to salt consumption in Australia. Asia Pacific journal of clinical nutrition. 2010; 19(4):550-4. [PubMed: 21147717]

27. Miller LM, Cassady DL. The effects of nutrition knowledge on food label use. A review of the literature. Appetite. 2015; 92:207-16. [PubMed: 26025086]

28. Sea salt vs. table salt. [database on the Internet]. American Heart Association; Available from: http://sodiumbreakup.heart.org/sodium-411/sea-salt-vs-table-salt/ [cited Accessed November 15, 2016]

29. Satya R, Dibakar C. Salt substitute from banana plant (Musa- balbisiana Colla). Journal of Chemical and Pharmaceutical Research. 2013; 5(6):155-9.

30. Hajjar IM, Grim CE, George V, Kotchen TA. Impact of diet on blood pressure and age-related changes in blood pressure in the US population: analysis of NHANES III. Archives of internal medicine. 2001; 161(4):589-93. [PubMed: 11252120]

31. Rossmann B, Muller H, Smalla K, Mpiira S, Tumuhairwe JB, Staver C, et al. Banana-associated microbial communities in Uganda are highly diverse but dominated by Enterobacteriaceae. Applied and environmental microbiology. 2012; 78(14):4933-41. [PubMed: 22562988]

32. Deka D, Talukdar N. Chemical and spectroscopic investigation of Kolakhar and its importance. Indian journal of traditional knowledge. 2007; 6(1):72-8.

33. Tarkodjiel M, Mbaiguinam M, Ngaram N, Mahmout Y, Allaramadji N. Elemental Composition of Vegetable Salts from Ash of Four Common Plants Species from Chad. International Journal of Pharmacology. 2012; 8(6):582-5. 


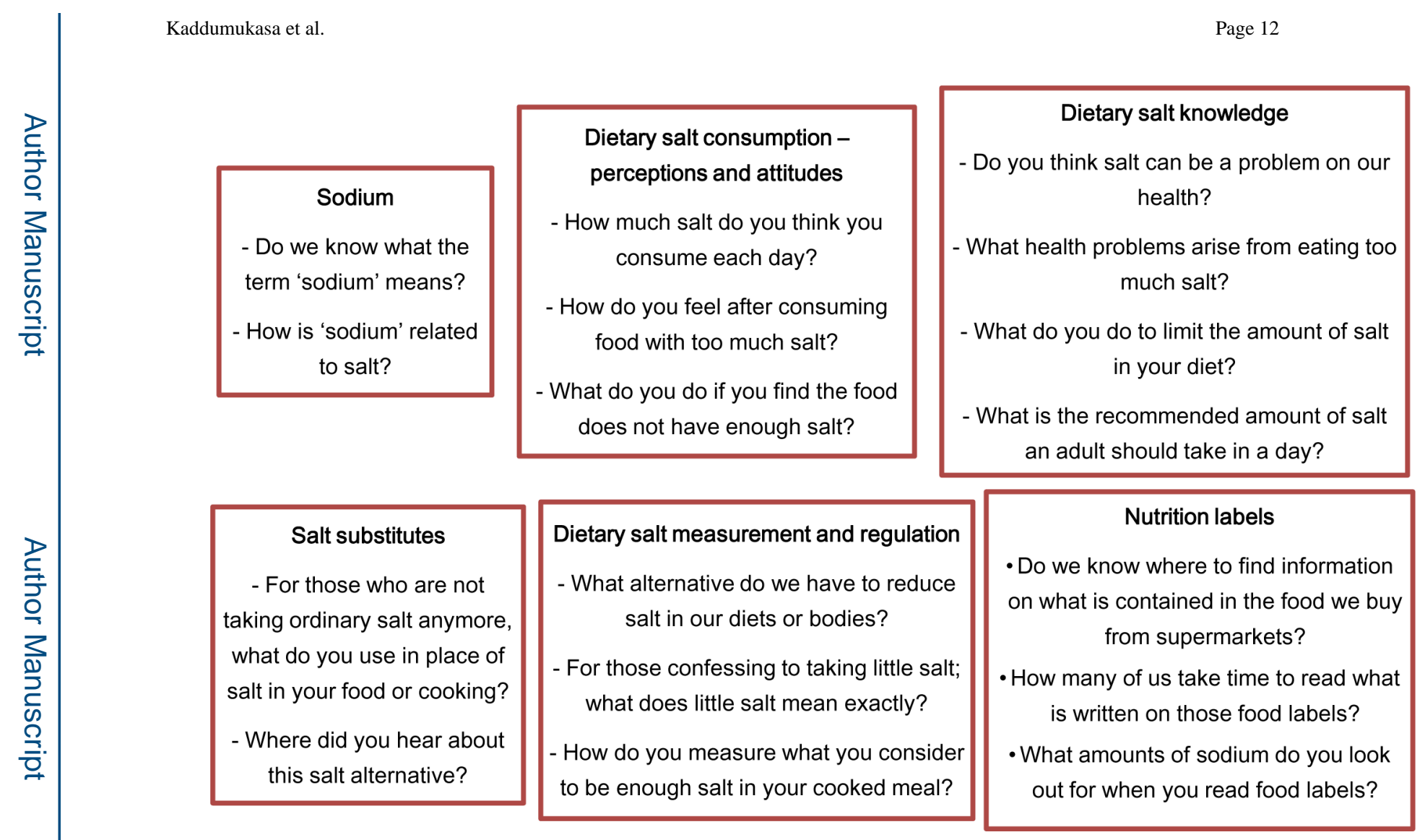

Figure 3.

Overview of the semi structured interview protocol 


\section{Prevalence of listed dietary salt perception(s)}

food with low salt is tasteless and inedible

high salt diet is a serious problem on health

raw salt is a serious problem on health

raw salt is inevitable with certain foods

Respondent adds raw salt to their food

raw salt is a bigger problem on health than a high salt diet

Initially indifferent but changed attitude after stroke diagnosis
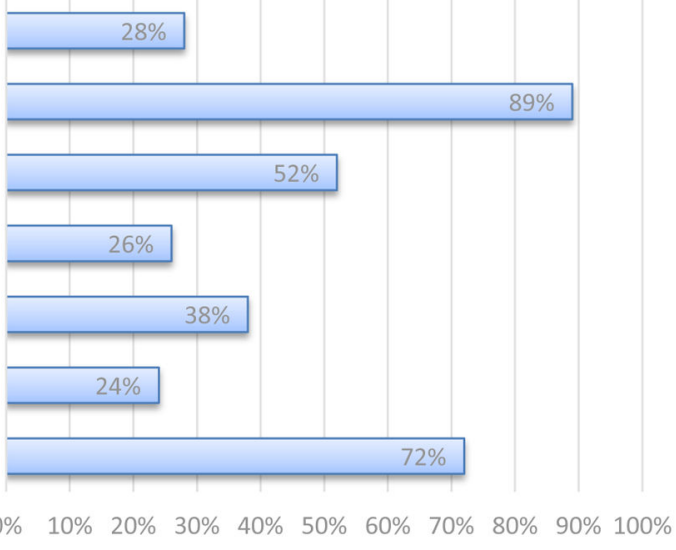

Figure 4.

Prevalence of common dietary salt consumption perceptions 
Table 1

Study group characteristics, prevalence of Salt-Disease knowledge, Adjusted OR by characteristics

\begin{tabular}{|c|c|c|c|}
\hline Characteristic (n) & $\%$ knowledgeable & $\begin{array}{c}\text { Odds Ratio }(95 \% \text { CI }) \\
\text { p-value }\end{array}$ & $\underset{\text { p-value }}{* \text { Odds Ratio }}(95 \%$ CI $)$ \\
\hline Total & $14.8 \%$ & & \\
\hline \multicolumn{4}{|l|}{ Sex } \\
\hline Men (28) & $28.6 \%$ & $4.90(1.33,18.1)$ & $5.77(1.38,24.20)$ \\
\hline Women (53) & $7.5 \%$ & $p=0.011$ & $\mathrm{p}=\mathbf{0 . 0 1 7}$ \\
\hline \multicolumn{4}{|l|}{ Age Group } \\
\hline$>45$ years $(60)$ & $16.7 \%$ & $1.80(0.36,9.01)$ & $1.86(0.37,9.43)$ \\
\hline$<45$ years $(20)$ & $10.0 \%$ & $\mathrm{p}=0.470$ & $\mathrm{p}=0.453$ \\
\hline \multicolumn{4}{|l|}{ Marital Status } \\
\hline Single/Divorced/Widowed (37) & $21.6 \%$ & $2.76(0.76,10.04)$ & $2.70(0.75,9.73)$ \\
\hline Married (44) & $9.1 \%$ & $\mathrm{p}=0.114$ & $\mathrm{p}=0.129$ \\
\hline \multicolumn{4}{|l|}{ Education } \\
\hline Low (None/Primary) (48) & $14.6 \%$ & $0.96(0.28,3.32)$ & \\
\hline High (Secondary/Higher) (33) & $15.2 \%$ & $\mathrm{p}=0.944$ & \\
\hline \multicolumn{4}{|l|}{ Stroke History } \\
\hline Hemorrhagic (20) & $30.0 \%$ & $3.85(1.10,14.29)$ & $3.85(1.10,14.29)$ \\
\hline Ischemic (61) & $9.8 \%$ & $\mathrm{p}=\mathbf{0 . 0 2 8}$ & $\mathrm{p}=\mathbf{0 . 0 3 6}$ \\
\hline History of stroke recurrence (12) & $16.7 \%$ & $1.18(0.22,6.20)$ & $1.18(0.23,6.19)$ \\
\hline No recurrent stroke (69) & $14.5 \%$ & $\mathrm{p}=0.845$ & $\mathrm{p}=0.842$ \\
\hline \multicolumn{4}{|l|}{ Time since stroke } \\
\hline$>2 \mathrm{yr}(33)$ & $24.2 \%$ & $3.52(0.96,12.87)$ & $3.29(0.94,11.52)$ \\
\hline$\leq 2 \mathrm{yr}(48)$ & $8.3 \%$ & $p=0.048$ & $\mathrm{p}=0.063$ \\
\hline \multicolumn{4}{|l|}{ Location } \\
\hline Urban (46) & $10.9 \%$ & $0.49(0.14,1.69)$ & $0.49(0.14,1.69)$ \\
\hline Rural (35) & $20.0 \%$ & $\mathrm{p}=0.252$ & $\mathrm{p}=0.258$ \\
\hline
\end{tabular}

* Adjusted for participant level of education 
Table 2

Samples of key quotations in the derived themes

\begin{tabular}{|c|c|c|c|}
\hline Theme & Sub-theme & Quotation & $\begin{array}{l}\text { Respondent (Gender, age, } \\
\text { post-stroke duration, No. } \\
\text { of recurrent strokes) }\end{array}$ \\
\hline \multirow[t]{7}{*}{ Perceptions, attitudes } & Strict adherence & $\begin{array}{l}\text { "With stroke you have to discipline yourself not to } \\
\text { eat raw or too much salt." }\end{array}$ & male, 51years, 3years, 0 \\
\hline & Poor adherence & $\begin{array}{l}\text { "My patient is stubborn, if you refuse to give him } \\
\text { salt he will refuse the food totally" }\end{array}$ & $\begin{array}{l}\text { caretaker of male, } 67 \text { years, } \\
\text { 6years, } 2\end{array}$ \\
\hline & Indifferent & $\begin{array}{l}\text { "I take the salt that is cooked in food by my wife } \\
\text { and I don't add." }\end{array}$ & male, 58years, 1year, 0 \\
\hline & $\begin{array}{l}\text { Owns salt consumption } \\
\text { choices }\end{array}$ & $\begin{array}{l}\text { "I instruct my caretaker to reduce the salt. She } \\
\text { sometimes disobeys but I still insist." }\end{array}$ & female, 85 years, 10 years, 0 \\
\hline & $\begin{array}{l}\text { Raw salt worse than } \\
\text { consistent high salt diet }\end{array}$ & $\begin{array}{l}\text { "Eating too much salt is bad however raw salt is } \\
\text { much worse." }\end{array}$ & female, 51years, 5years, 0 \\
\hline & Erroneous perceptions & $\begin{array}{l}\text { "Salt accumulates in our blood vessels causing } \\
\text { stroke." }\end{array}$ & male, 58years, 4years, 1 \\
\hline & & $\begin{array}{l}\text { "Too much salt makes lots of fats which block the } \\
\text { veins." }\end{array}$ & male, 55years, 4years, 0 \\
\hline \multirow[t]{2}{*}{ Salt Knowledge } & $\begin{array}{l}\text { Know high salt is bad but do } \\
\text { not know why }\end{array}$ & $\begin{array}{l}\text { "My doctor told me not to take too much salt since } \\
\text { Igot this stroke, but I don't know why" }\end{array}$ & male, 58years, 1year, 0 \\
\hline & Sodium is unknown & "I do not know sodium, but I understand salt" & male, 65years, 3years, 0 \\
\hline Salt measurement & & $\begin{array}{l}\text { "We use hands or pinches to measure salt. Cooking } \\
\text { experience determines amount of salt" }\end{array}$ & female, 68years, 1year, 0 \\
\hline
\end{tabular}




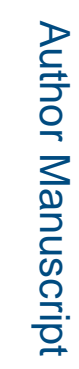

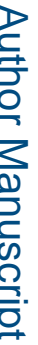

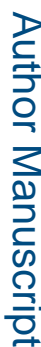

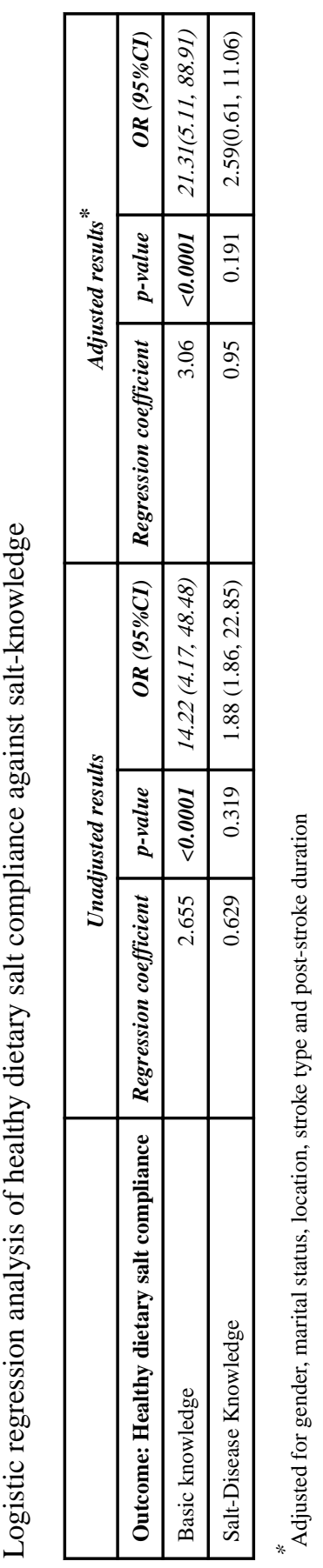

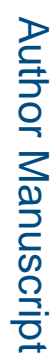

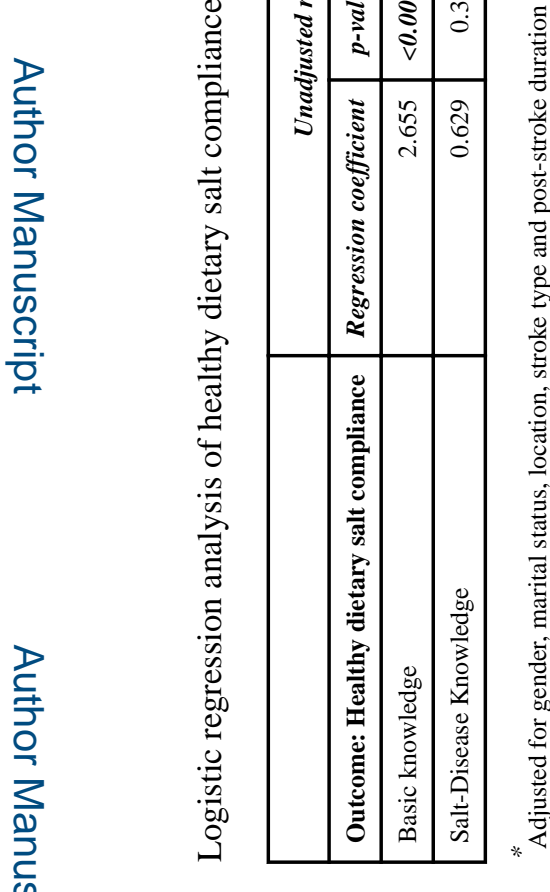

J Stroke Cerebrovasc Dis. Author manuscript; available in PMC 2018 December 01 